\title{
Changes in health-related quality of life: a compensating income variation approach
}

\author{
by
}

\author{
Paul McNamee ${ }^{\ddagger}$ and Silvia Mendolia ${ }^{\dagger}$ \\ † University of Wollongong, School of Accounting, Economics and Finance \\ ‡ University of Aberdeen, Health Economics Research Unit
}

\author{
Corresponding Author: \\ Dr. Silvia Mendolia \\ School of Accounting, Economics and Finance \\ Faculty of Business \\ Building 40, Room 215 \\ University of Wollongong NSW 2522
}

Other Author:

Dr. Paul McNamee

Health Economics Research Unit

University of Aberdeen

Polwarth Building

Foresterhill

Aberdeen AB25 2ZD

Scotland 


\section{Abstract:}

This paper investigates the relationship between negative changes in health and life satisfaction, using a large, nationally represenative sample from the Household, Income and Labour Dynamics of Australia Survey. We use panel data models with fixed effects and estimate the life satisfaction impact of several different changes in SF-6D to calculate the Compensating Income Variation (CIV) of them.

Our work innovates with respect to the existing literature by using a more robust CIV method that takes account of potential measurement error in income. Further, we produce the first set of monetary values for deteriorations in health, using SF-6D utility values, one of the main measures used to estimate and value health change for economic evaluation (Brazier et al., 2002). We show that negative changes in SF-6D are significantly associated with a reduction in life satisfaction, and the results suggest that the starting point matters: a drop of 0.1 in SF-6D score is associated with a decrease of 0.12 points in life satisfaction if the starting utility value is 0.8 , but the effect is $100 \%$ higher if the SF-6D starting point is 0.7. More generally, we find that a 0.1 deterioration in SF-6D has a strong association with life satisfaction and that the CIV value is substantial (over US\$120,000).

Keywords: Life satisfaction; SF-6D; Well-being

JEL Codes: I10; I12 


\section{Introduction}

Individuals' valuations of health changes are essential in order to establish the value for money of competing health care interventions. For example, evaluations of health changes have become increasingly important in calculating compensations for injured individuals after health losses, including tangible and intangible damages (Ferrer-i-Carbonell and van Praag 2002). Further, preventative interventions also require an estimate of the impact of these changes, to judge relative cost-effectiveness.

So far, the predominant economic evaluation approach in the health economics literature has been Cost-Utility Analysis. This provides estimates of changes in health by measuring changes in Quality Adjusted Life Years (QALYs). The quality of life component is measured by preferencebased health related instruments, such as the EQ-5D and SF-6D, although increasingly a number of diseases-specific measures are available (see Brazier et al. 2012 and Nimdet et al., 2015). However, a key issue with this method is that the decision-rules of Cost Utility Analysis require monetary valuation of QALYs. It is common for researchers and policy-makers to use a single value ( $£ 30,000$ per QALY gained), or a value range (£20,000-£30,000) (NICE, 2013), but these have limited empirical support (Grosse 2008; Claxton et al 2015). For researchers who wish to apply Cost-Benefit Analysis, a number of studies have provided estimates of willingness to pay for health state changes (see for example Johnson et al. 2000; Chuck et al. 2009; Kløjgaard et al. 2014). However, these estimates have several limitations. In particular, interpersonal comparability has been questioned and sample selection bias is likely to affect the results from this type of methodology (Heckman 1979). Further, inviting people to consider situations that they have never directly experienced is problematic and hypothetical preference-based valuation methods have a number of drawbacks (Loomis 2014; Fujiwara and Dolan, 2014). For all of these reasons, it is important to consider other approaches that are less reliant on responses to hypothetical questions. 
One possible approach is the Subjective Well-Being valuation method, also known as Compensating Income Variation (CIV), which can be used to estimate monetary values for health states and other welfare changes. Monetary valuation allows comparisons between different health conditions and can be useful in informing policy recommendations (McNamee and Mendolia 2014; Brown 2015). Further, monetary valuation using well-being measures may provide information over and above QALYs, as the benefits from some health interventions may have effects on aspects of an individual's life, which are not captured by health-related quality of life measures (see Powdthavee and van den Berg 2011; Fujiwara and Dolan 2014; Brown 2015; and Pelo et al., 2017, for a discussion of quality of life measures in the context of health procedures).

The CIV method has been applied in the literature to value the effects of several health conditions, such as chronic pain (McNamee and Mendolia 2014); migraine (Groot and Massen van den Brink 2004); cardio-vascular diseases (Groot and Massen van den Brink 2006); chronic conditions (Ferrer-I-Carbonell \& van Praag 2002; Powdthavee and van den Berg 2011; Asgeirsdottir et al. 2017; Howley 2017;), disability (Oswald and Powdthavee 2008); and general health (Brown 2015). To date however, no prior research has been conducted to estimate valuation of generic preference-based health state measures that are commonly used to compute QALYs.

Using SF-6D valuations from the SF-36 health measure, this paper investigates the relationship between health losses and individuals' life satisfaction. In keeping with the CIV methodology, which focuses on compensation for reductions in welfare, we focus only on health losses.

To the best of our knowledge, this is the first paper to apply the CIV method to value health losses measured by changes in the SF-6D (Brazier et al. 2002).

Related literature includes Brown (2015), who analyses the impact of self-assessed health on life satisfaction, instrumenting health changes and income using a proxy for intelligence, a distance instrument and the health status of similar individuals who are geographically separated. Brown (2015) uses repeated cross sections from the General Social Survey, and therefore cannot take 
advantage from repeated observations from the same individuals. We complement this existing evidence, by using SF-6D as a more complete measure of health, and by analysing longitudinal data, and therefore controlling for individual characteristics that do not vary over time.

Most of the existing literature calculating valuations of health does not correct for income endogeneity. The resulting CIV estimates might be significantly higher than the corrected estimates because of measurement error (Groot and Massen van den Brink 2004 and 2006; Powdthavee and van den Berg 2011). Howley (2017) addressed this issue using parental education as an instrument for income, assuming that parental education only affects life satisfaction through individual income. However, parental education is likely to affect well-being through a variety of other channels, such as social networks, wealth, expectations, etc. Brown (2015) instruments income using a measure of intelligence, a distance instrument and the health of similar people, and therefore assumes that these variables do not directly affect life satisfaction.

To circumvent these issues, we adopt an innovative methodology proposed by Frijters et al. (2011), using unexpected income shock to address income endogeneity.

Our second contribution is that we directly focus on the valuation of health changes as measured by SF-6D, rather than valuation of the levels themselves. Valuation of change has been neglected somewhat in the health state valuation literature. For example, the values that underpin QALY calculations are not derived from direct valuation of the change in health; rather, they are typically valued relative to perfect health and death states. Valuation of change is important as the value function may be non-linear, e.g. the life satisfaction equivalence of a 0.1 change on a 0-10 scale may depend on the starting point on that scale.

The rest of this paper is organized as follows. Section 2 describes the data and briefly presents SF-6D and well-being indicators. Section 3 discusses the estimation methods and Section 4 presents the main results. Section 5 concludes.

\section{Data}


We use data from ten waves of the Household, Income and Labour Dynamics Survey (HILDA) Survey, which is a household representative longitudinal study of the Australian population that started in 2001 , including a total of 13,969 individuals in 7,682 households (Wooden and Watson, 2002).

HILDA respondents answer the following question: all things considered, how satisfied are you with your life? They can then pick a number from 0 to 10 , where 0 means "totally dissatisfied" and 10 means "totally satisfied". Table 1 presents the distribution of life satisfaction in the estimation sample. There are a small percentage of individuals who report low satisfaction ( $0-4$ on a $0-10$ scale) (2\%), but this percentage substantially increases when we analyse the distribution of life satisfaction among individuals with low SF-6D (up to 7.7\%) (see Table A8).

SF-6D is a preference-based measure of general health status based on the SF-36 (Brazier et al., 1998; Brazier et al., 2002). SF-6D can be used to generate QALYs for cost-utility analysis. It enables any patient who has completed the SF-36 to be classified according to a six-dimensional health classification system comprising physical functioning, role limitations, social functioning, pain, mental functioning, and vitality (Whitehead and Ali 2010). A particular SF-6D health state is defined by choosing one statement from each dimension (Brazier et al. 2002) (see tables A1-A5 in the online Appendix).

The SF-6D utility weights are available in HILDA for each respondent and vary from 0.29 to 1 (with 1 defining full health) (Brazier et al. 2002) (see Figure A1 in the online Appendix).

Previous literature has analysed the concept of Minimally Important Difference (MID) for SF6D (Walters and Brazier, 2003 and 2005), defined as the smallest difference in the score which would be perceived as beneficial by the patient and would imply a change in treatment plan. In particular, Walters and Brazier (2005, p. 1526) show that the "MID for SF-6D ranged from 0.011 to 0.097 ". 
HILDA also includes Australian SF-6D weights (Norman et al. 2014). However, we use the standard SF-6D weights based on Brazier et al. (2002), in order to facilitate comparability with previous studies, and be able to analyse the impact of changes according to the Minimally Important Difference. Further, weights elaborated by Brazier et al. 2002 were constructed using a representative community sample (rather than an online panel, as in Norman et al. 2014) and this is an important advantage.

We use three different approaches to calculate the monetary value of deteriorations in SF-6D scores, in order to capture a broad picture of the impact of health changes on individual well-being.

We focus on the valuation of changes in SF-6D (rather than values of the utility scores themselves), as these are the important parameters to consider when valuing health interventions.

First, we analyse the life satisfaction impact and CIV of changes in the SF-6D score across two consecutive waves, using the value of the index rounded to one decimal point and focusing on the life satisfaction effect of health losses across the most commonly observed SF-6D values, between 0.6 and 0.9 (see Figure A1 and Table A6- over $85 \%$ of individuals in HILDA reports scores in this range).

Second, we refer to the concept of MID analysed in Walters and Brazier (2005), and calculate the actual loss in SF-6D across two consecutive waves. We then analyse the life satisfaction effect and CIV of several deteriorations in SF-6D, ranging from 0.01 to 0.1 . In this second approach, we focus on the size of the change (0.01 to 0.1$)$, rather than on the specific scores (see Table A7).

Lastly, we analyse a model in which all changes across SF-6D utility scores are interacted with the size of the deterioration, in order to combine the two previous approaches (i.e. a SF-6D loss of 0.03 in a $0.7-0.6$ change might be different from a health loss of the same size in a 1-0.9 change). 
We use an extensive set of control variables, to account for other factors that may influence life satisfaction, such as individual education, gender, employment and marital status, number and age of children, home ownership, geographic remoteness, and time binary variables (We follow Frijiters et al. 2004 and do not control simultaneously for age, time and fixed-effects. We therefore do not include age as a covariate and note that the time dummies will include age effects.).

We also control for life events that took place in the last 12 months (personal injury or illness, victim of physical violence, death of a family member, victim of a property crime). The list of variables included in our model is reported in Table 3 . The final sample includes over 83,000 observations of around 15,700 individuals with non-missing information on SF-6D and other information on the individual and family characteristics (see Table A10 for descriptive statistics).

\section{Estimation}

We begin our analysis by estimating life satisfaction (measured on a 0-10 scale) as a function of health $\mathrm{H}$, individual characteristics $\mathrm{X}$, and income windfall $\mathrm{Y}$.

We assume an underlying indirect life satisfaction function (LS*):

$$
\mathrm{LS}^{*}=\mathrm{LS}^{*}[\mathrm{H}, \mathrm{X}, \mathrm{Y}]
$$

The standard approach in the literature calculating CIV for health conditions is to include annual income (or the logarithm of it) as a separate variable in the life satisfaction equation and then calculate the CIV by using the trade-off between the effects of income and health on life satisfaction (Groot and Maassen van den Brink 2004 and 2006; Carroll et al. 2009; McNamee and Mendolia 2014; Powdthavee and van den Berg 2011).

In this case, life satisfaction is assumed to be a linear function of a vector of binary variables representing SF6D changes $H_{i t}$, logarithm of household yearly income, $Y_{i t}$, , and other individual characteristics $X_{i t}$ :

$$
L S_{i t}=\alpha+\boldsymbol{\beta}_{1}{ }^{\prime} H_{i t}+\beta_{2} \log Y_{i t}+\boldsymbol{\beta}^{\prime} X_{i t}+\varepsilon_{i t}+c_{i}
$$


Under this specification, the CIV of health changes can be calculated as

$$
C I V=\left\{\exp \left(\frac{\beta_{1}}{\beta_{2}}\right)-1\right\} * Y i d
$$

Where $Y_{\text {id }}$ is the average equivalised daily income (see for example McNamee and Mendolia 2014; Powdthavee and van den Berg 2011, Howley 2017).

However, this approach has some drawbacks, and in particular assumes that income changes are completely independent of changes in health status, while in reality observed changes in income are often related to changes in life circumstances, and both can be also connected (or determined by) to changes in health.

As noted in Frijters et al. (2011) and Howley (2017), there are several reasons to believe that the impact of income on life satisfaction is downward biased because of endogeneity, and this would lead to inaccurately large estimates of CIVs (Clark et al 2008). In particular, one possible source of endogeneity is measurement error in income, which can bias the effect of income on life satisfaction towards zero. Further, unobserved characteristics which may be correlated with both income and life satisfaction, may drive the results. For example, income is likely to be positively correlated with factors such as working hours, commuting time, stress, etc. and these factors could be related to life satisfaction, and may lead to downward biased estimates (Powdthavee 2009).

For these reasons, we do not include a continuous income variable in the model, but rather follow the methodology proposed in Frijters et al. (2011) and use instead an indicator variable equal to 1 if the individual reported a major improvement in finances, as detailed below.

Establishing a causal relationship between changes in health and life satisfaction is complex from an empirical point of view, as people with better health may have unobserved characteristics (such as personality traits, time preferences, etc.) that also affect their life satisfaction. Further, different people answer these questions in a different way, according to their own interpretation of particular scores. 
For these reasons, coefficients obtained from regression analysis using Ordinary Least Squares (OLS) methods are likely to be biased estimates of the true effects. Unfortunately, the data does not include any quasi-experimental variation across the sample that can be exploited in order to address potential selection on unobservables. Further, it is challenging to identify an instrumental variable that is correlated with changes in health but uncorrelated with the error terms in the life satisfaction equation. Recent studies using instrumental variable estimation in the context of health have shown that it is problematic to detect such variables (see for example Almond 2006; Rees and Sabia 2011; and Cawley and Meyeroefer 2012) and using a nonexogenous instrument could lead to inconsistent and biased estimates of the true effects (Murray 2006).

We therefore estimate a model with individual fixed effects, in order to take into account time invariant unobserved characteristics that might have an effect on life satisfaction, such as personality traits, cultural background, risk aversion, ability, etc. Further, we include additional independent variables, such as education, employment, region of residence, house tenure, and a range of other characteristics and negative life events (e.g. being the victim of violence, property crime, death or serious illness of a family member or close friend, etc.).

Therefore, life satisfaction is assumed to be a linear function of a vector of binary variables representing SF-6D, $H_{i}$, positive income windfall, $Y_{i t}$, and other individual characteristics $X_{i t}$ :

$$
L S_{i t}=\alpha+\boldsymbol{\beta}_{1}{ }^{\prime} H_{i t}+\beta_{2} Y_{i t}+\boldsymbol{\beta}_{3}{ }^{\prime} X_{i t}+\varepsilon_{i t}+c_{i}
$$

Where $\beta_{1}$ is a vector of coefficients of changes in SF-6D and $c_{i}$ is an individual fixed effect that takes into account time-invariant unobserved heterogeneity.

We begin by estimating the life satisfaction effect of a series of specific deteriorations in SF6D: from 1 to 0.9 ; from 0.9 to 0.8 ; from 0.8 to 0.7 ; from 0.7 to 0.6 ; changes to 0.8 from a value 
higher than 0.9 ; changes to 0.7 from a value higher than 0.8 ; changes to 0.6 from a value higher than 0.7; and all other negative changes (to values smaller than 0.6).

We construct a set of binary variables corresponding to the various changes and include all these variables (and a binary variable equal to 1 if individuals do not experience any change in SF-6D score across two waves) in the model.

In the second version of the model, we focus on the size of the changes, rather than on the specific SF-6D values in $\mathrm{t}-1$ and $\mathrm{t}$.

We estimate the effect of a vector of binary variables representing different health losses in SF-6D betweent-1 and t, ranging between -0.01 and -0.1 (10 binary variables representing changes, e.g. one variable for each change: equal to $-0.1 ;-0.09 ;-0.08$, etc.); and one binary variable for negative changes larger than -0.1 , to be consistent with the definition of MID in Walters and Brazier (2005).

Lastly, we construct a model in which we interact the most common deteriorations in SF-6D (from 0.9 to 0.8 ; from 0.8 to 0.7 and from 0.7 to 0.6 ) with the size of each change (from -0.01 to less than -0.1).

In all three models, individuals experiencing a loss in SF-6D are compared with the average individual experiencing any improvement in SF-6D scores. We have run a sensitivity test including both positive and negative SF-6D changes and omitting the group with no changes. Main results for negative changes were stable. We therefore decided to concentrate on health losses and only include negative changes.

In the fixed effects model, the causal interpretation of results relies on the assumption that the time-dependent error term is independent of changes in SF-6D, conditional on the regressors included in the model and on the individual fixed effect. This assumption will not hold if there are unobserved random shocks that affect SF-6D and life satisfaction. For this reason, we control for a wide set of individual characteristics, as well as for negative life events. 
We use the parameter estimates from (4) to calculate the CIV of the different changes in SF6D, following the approach presented in Frijters et al. (2011).

In particular, we calculate the magnitude of "financial improvements" that would be needed to compensate an individual for a specific deterioration in SF-6D score.

Therefore, we calculate the following ratio:

$$
\text { CIV ratio }=\frac{\beta_{1}}{\beta_{2}}
$$

Further, we convert the CIV ratio into a monetary value by multiplying it by the mean windfall income associated with a "major improvement in finances" in our sample.

Following Frijters et al. (2011), we calculate this estimate using the mean change in income experienced by individuals between 18 and 70 years old in the estimation sample who report a "major improvement in finance" and an increase in the household gross income (A $\$ 106,718)$. The exact question in the HIDLA survey is: "We now would like you to think about major events that have happened in your life over the past 12 months. For each statement cross YES or NO to indicate whether each event happened in the last 12 months" - "Major improvement in financial situation (e.g. won lottery, received an inheritance)"

This methodology is well-established and has been applied to calculate the CIV of several life events, such as changes in financial situation, marriage breakup, major illness, and death of a relative or friend in Frijters et al (2011) and similarly in Johnston et al. (2017) to calculate the compensation for crime victims.

One natural concern is that the financial improvement variable is not exogenous and that people who are more likely report these payments may also be different from the general population. Au and Johnston (2015) have shown that this variable is not statistically associated with receipt of accident or illness insurance, workers compensation, life insurance, or redundancy payments, suggesting that it should not be influenced by time-varying characteristics that might 
also affect health status. Further evidence is provided by Johnston et al (2017), who use HILDA data and showed that the occurrence of an income shock in the next 12 months is not associated with demographic or socio-economic characteristics after controlling for individual-area fixed effects.

Similarly, we verified that receiving a positive income shock in the next 12 months is not determined by household income and socio-economic status, or by any major illness or long term health condition in the previous period, and any other life event, once we control for fixed effects (see Appendix Table A11).

\section{Results}

The main results from the estimation are presented in Tables 1-5.

We present results from three specifications of the fixed effects model, where additional independent variables are included, in order to show the stability of our results.

Changes in SF-6D have a large and significant association with life satisfaction for individuals in our sample. The size of the effect slightly decreases when we include additional independent variables, and in particular when we include significant life events, but remains significantly different from zero.

In the first version of the model (Table 1), we estimate the effect of specific losses in SF-6D on individuals' life satisfaction, comparing individuals who experienced health losses to the average individual who experience an improvement in SF-6D utility scores.

Negative changes in SF-6D from 0.7 to 0.6 and 0.8 to 0.7 are associated with a strong decrease in life satisfaction ( 0.24 to 0.12 points, or $16 \%$ to $8 \%$ of a standard deviation). Bigger changes resulting in a SF-6D value of 0.6 or 0.7 have similar effects, while changes that result in a value lower than 0.6 have an even higher impact on life satisfaction (up to 0.6 points, or $40 \%$ of a standard deviation). 
Our results also show a positive relationship between income and life satisfaction and this is consistent with previous literature (Mentzakis et al. 2012; Groot and Maassen van den Brink 2004 and 2006). Experiencing a financial improvement significantly increases individuals' life satisfaction by around 0.12 points ( $8 \%$ of a standard deviation).

Table 2 presents results from the second approach, where we focus on the size of the change in SF-6D from t-1 to $t$ and include 11 variables indicating various changes in SF-6D in the model. We then estimate the life satisfaction effect for a person experiencing a particular change compared to an average individual having any improvement in SF-6D score between t-1 and t.

The life satisfaction impact of SF-6D changes varies by the size of the change, between 0.03 and 0.23 points (from $2 \%$ to $16 \%$ of a standard deviation). As expected, the strongest effects come from the biggest variations (-0.1 points in SF-6D scores). 
Table 1- The effect of one specific change in SF-6D on life satisfaction-Overall sample

\begin{tabular}{|c|c|c|c|}
\hline & Model 1 & Model 2 & Model 3 \\
\hline \multicolumn{4}{|c|}{$\begin{array}{l}\text { Changes in SF-6D (rounded } \\
\text { at } 1 \text { decimal point) from } t-1 \\
\text { to } t\end{array}$} \\
\hline No change & $\begin{array}{l}0.008 \\
(0.009)\end{array}$ & $\begin{array}{l}0.008 \\
(0.009)\end{array}$ & $\begin{array}{l}0.006 \\
(0.009)\end{array}$ \\
\hline SF-6D from 0.7 to 0.6 & $\begin{array}{l}-0.245 \\
(0.025)^{* *}\end{array}$ & $\begin{array}{l}-0.246 \\
(0.025)^{* *}\end{array}$ & $\begin{array}{l}-0.242 \\
(0.025)^{* * *}\end{array}$ \\
\hline SF-6D from 0.8 to 0.7 & $\begin{array}{l}-0.120 \\
(0.016)^{* *}\end{array}$ & $\begin{array}{l}-0.121 \\
(0.016)^{* *}\end{array}$ & $\begin{array}{l}-0.119 \\
(0.016)^{* *}\end{array}$ \\
\hline SF-6D from 0.9 to 0.8 & $\begin{array}{l}-0.008 \\
(0.012)\end{array}$ & $\begin{array}{l}-0.012 \\
(0.012)\end{array}$ & $\begin{array}{l}-0.011 \\
(0.012)\end{array}$ \\
\hline SF-6D from 1 to 0.9 & $\begin{array}{l}0.008 \\
(0.031)\end{array}$ & $\begin{array}{l}0.001 \\
(0.031)\end{array}$ & $\begin{array}{l}-0.001 \\
(0.032)\end{array}$ \\
\hline SF-6D from $>0.7$ to 0.6 & $\begin{array}{l}-0.244 \\
(0.022)^{* *}\end{array}$ & $\begin{array}{l}-0.243 \\
(0.022)^{* *}\end{array}$ & $\begin{array}{l}-0.230 \\
(0.022)^{* *}\end{array}$ \\
\hline SF-6D from $>0.8$ to 0.7 & $\begin{array}{l}-0.112 \\
(0.027)^{* *}\end{array}$ & $\begin{array}{l}-0.118 \\
(0.027)^{* *}\end{array}$ & $\begin{array}{l}-0.108 \\
(0.026)^{* *}\end{array}$ \\
\hline SF-6D from $>0.9$ to 0.8 & $\begin{array}{l}0.006 \\
(0.057)\end{array}$ & $\begin{array}{l}0.003 \\
(0.057)\end{array}$ & $\begin{array}{l}-0.002 \\
(0.057)\end{array}$ \\
\hline $\begin{array}{l}\text { Other neg. changes (to } \\
<0.6 \text { ) }\end{array}$ & $\begin{array}{l}-0.627 \\
(0.036)^{* *}\end{array}$ & $\begin{array}{l}-0.618 \\
(0.035)^{* *}\end{array}$ & $\begin{array}{l}-0.590 \\
(0.035)^{* *}\end{array}$ \\
\hline Financial improvements & $\begin{array}{l}0.121 \\
(0.022)^{* *}\end{array}$ & $\begin{array}{l}0.123 \\
(0.022)^{* *}\end{array}$ & $\begin{array}{l}0.124 \\
(0.022)^{* *}\end{array}$ \\
\hline $\begin{array}{l}\text { Control for Employment, } \\
\text { Marital Status and other } \\
\text { socio-economic factors }\end{array}$ & No & Yes & Yes \\
\hline $\begin{array}{l}\text { Control for personal illness, } \\
\text { victim of violence and other } \\
\text { life events }\end{array}$ & No & No & Yes \\
\hline N. Observations & 83,556 & 83,530 & 83,177 \\
\hline
\end{tabular}

Notes: Robust standard errors are in brackets * indicates that the underlying coefficient is significant at $10 \%$ level, ** at $5 \%$ and $* * *$ at $1 \%$.

SF-6D scores are approximated at 1 decimal point ( 0.65 is approximated to $0.7 ; 0.75$ is approximated to 0.8 , etc). These results have been tested by estimating a model using SF-6D rounded at two decimal points and defining SF-6D equal to 0.6 if the actual score is between 0.58 and 0.62 ; etc. Results are not reported for parsimony but are available on request and very similar to the ones in this Table. 
Table 2 - The effect of changes in SF-6D on life satisfaction - Overall sample - Different changes (all variables included in the model.)

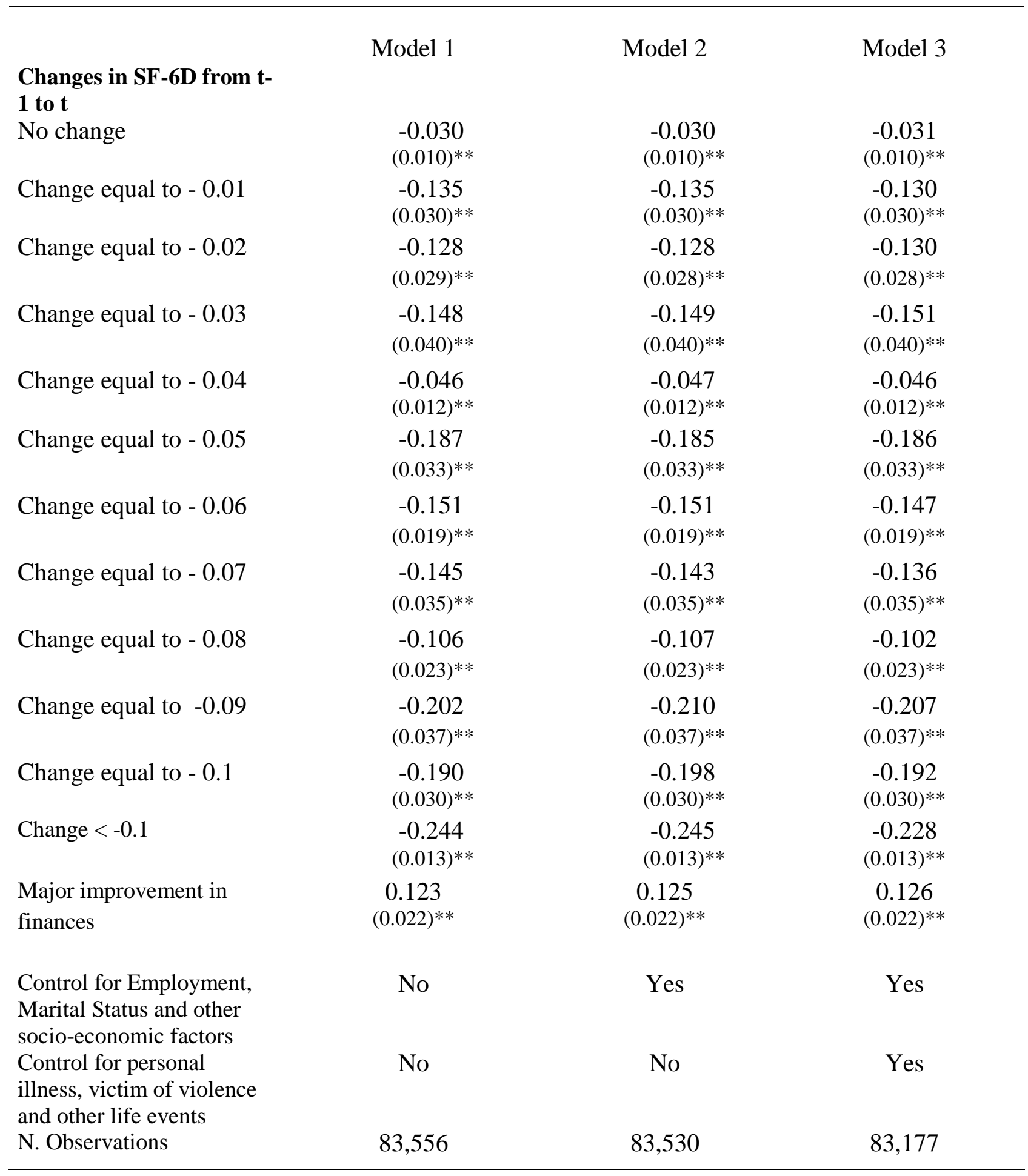

Note: Robust standard errors are in brackets * indicates that the underlying coefficient is significant at $10 \%$ level, ** at $5 \%$ and $* * *$ at $1 \%$. A change is defined equal to 0.1 if the actual value of the difference in SF-6D scores between $\mathrm{t}-1$ and $\mathrm{t}$ is between 0.095 (included) and 0.105 ; equal to 0.09 if the actual change is between 0.085 (included) and 0.095 , etc. 
The analysis of results presented in Tables 1 and 2 show that it is important to consider both the size of the change and the resulting SF-6D score. For this reason, we estimate a model including interactions between the most common changes in SF-6D (between 0.6 and 0.9) and the sizes of the changes (between 0.01 and 0.1). Interestingly, results in Table 3 show that the strongest effects are found when individuals move to a SF-6D score of 0.6. These changes decrease individual life satisfaction by 0.17 to 0.33 points ( $12 \%$ to $23 \%$ of a standard deviation).

Table 3 - The effect of changes in SF-6D on life satisfaction - Overall sample - Interaction between specific changes and their size

\begin{tabular}{|c|c|c|c|}
\hline & Model 1 & Model 2 & Model 3 \\
\hline SF-6D from 0.7 to $0.6^{*}(-0.01)$ & $\begin{array}{c}0.146 \\
(0.229)\end{array}$ & $\begin{array}{c}0.134 \\
(0.231)\end{array}$ & $\begin{array}{c}0.089 \\
(0.222)\end{array}$ \\
\hline SF-6D from 0.7 to $0.6^{*}(-0.02)$ & $\begin{array}{l}-0.194 \\
(0.235)\end{array}$ & $\begin{array}{l}-0.207 \\
(0.235)\end{array}$ & $\begin{array}{l}-0.251 \\
(0.239)\end{array}$ \\
\hline SF-6D from 0.7 to $0.6^{*}(-0.03)$ & $\begin{array}{c}0.044 \\
(0.126)\end{array}$ & $\begin{array}{c}0.054 \\
(0.129)\end{array}$ & $\begin{array}{c}0.027 \\
(0.129)\end{array}$ \\
\hline SF-6D from 0.7 to $0.6^{*}(-0.04)$ & $\begin{array}{l}-0.183 \\
(0.063)^{* *}\end{array}$ & $\begin{array}{l}-0.181 \\
(0.062)^{* *}\end{array}$ & $\begin{array}{l}-0.181 \\
(0.062)^{* *}\end{array}$ \\
\hline SF-6D from 0.7 to $0.6^{*}(-0.05)$ & $\begin{array}{l}-0.197 \\
(0.095)^{*}\end{array}$ & $\begin{array}{l}-0.200 \\
(0.093)^{*}\end{array}$ & $\begin{array}{l}-0.220 \\
(0.094)^{*}\end{array}$ \\
\hline SF-6D from 0.7 to $0.6^{*}(-0.06)$ & $\begin{array}{l}-0.113 \\
(0.056)^{*}\end{array}$ & $\begin{array}{l}-0.104 \\
(0.055)+\end{array}$ & $\begin{array}{l}-0.101 \\
(0.056) *\end{array}$ \\
\hline SF-6D from 0.7 to $0.6^{*}(-0.07)$ & $\begin{array}{l}-0.212 \\
(0.114)+\end{array}$ & $\begin{array}{l}-0.208 \\
(0.112)+\end{array}$ & $\begin{array}{l}-0.208 \\
(0.112)^{*}\end{array}$ \\
\hline SF-6D from 0.7 to $0.6^{*}(-0.08)$ & $\begin{array}{l}-0.156 \\
(0.090)+\end{array}$ & $\begin{array}{l}-0.154 \\
(0.090)+\end{array}$ & $\begin{array}{l}-0.168 \\
(0.092)^{*}\end{array}$ \\
\hline SF-6D from 0.7 to $0.6^{*}(-0.09)$ & $\begin{array}{l}-0.204 \\
(0.071)^{* *}\end{array}$ & $\begin{array}{l}-0.218 \\
(0.071)^{* *}\end{array}$ & $\begin{array}{l}-0.207 \\
(0.071)^{* *}\end{array}$ \\
\hline SF-6D from 0.7 to $0.6^{*}(-0.1)$ & $\begin{array}{l}-0.341 \\
(0.078)^{* *}\end{array}$ & $\begin{array}{l}-0.342 \\
(0.078)^{* *}\end{array}$ & $\begin{array}{l}-0.335 \\
(0.078)^{* *}\end{array}$ \\
\hline SF-6D from 0.7 to $0.6^{*}(<-0.1)$ & $\begin{array}{l}-0.201 \\
(0.048)^{* *}\end{array}$ & $\begin{array}{l}-0.205 \\
(0.048)^{* *}\end{array}$ & $\begin{array}{l}-0.190 \\
(0.048) * *\end{array}$ \\
\hline SF-6D from 0.8 to $0.7 *(-0.01)$ & $\begin{array}{c}0.041 \\
(0.159)\end{array}$ & $\begin{array}{c}0.018 \\
(0.156)\end{array}$ & $\begin{array}{c}0.014 \\
(0.154)\end{array}$ \\
\hline SF-6D from 0.8 to $0.7 *(-0.02)$ & $\begin{array}{c}0.041 \\
(0.079)\end{array}$ & $\begin{array}{c}0.051 \\
(0.077)\end{array}$ & $\begin{array}{c}0.049 \\
(0.077)\end{array}$ \\
\hline SF-6D from 0.8 to $0.7 *(-0.03)$ & $\begin{array}{c}0.036 \\
(0.116)\end{array}$ & $\begin{array}{c}0.040 \\
(0.116)\end{array}$ & $\begin{array}{c}0.034 \\
(0.117)\end{array}$ \\
\hline SF-6D from 0.8 to $0.7 *(-0.04)$ & $\begin{array}{c}0.019 \\
(0.078)\end{array}$ & $\begin{array}{c}0.011 \\
(0.080)\end{array}$ & $\begin{array}{c}0.016 \\
(0.080)\end{array}$ \\
\hline SF-6D from 0.8 to $0.7 *(-0.05)$ & $\begin{array}{l}-0.075 \\
(0.072)\end{array}$ & $\begin{array}{l}-0.064 \\
(0.072)\end{array}$ & $\begin{array}{l}-0.069 \\
(0.072)\end{array}$ \\
\hline SF-6D from 0.8 to $0.7 *(-0.06)$ & $\begin{array}{l}-0.056 \\
(0.044)\end{array}$ & $\begin{array}{l}-0.061 \\
(0.043)\end{array}$ & $\begin{array}{l}-0.063 \\
(0.044)\end{array}$ \\
\hline SF-6D from 0.8 to $0.7 *(-0.07)$ & $\begin{array}{l}-0.041 \\
(0.082)\end{array}$ & $\begin{array}{l}-0.039 \\
(0.081)\end{array}$ & $\begin{array}{l}-0.038 \\
(0.082)\end{array}$ \\
\hline SF-6D from 0.8 to $0.7 *(-0.08)$ & $\begin{array}{c}0.010 \\
(0.045)\end{array}$ & $\begin{array}{c}0.012 \\
(0.045)\end{array}$ & $\begin{array}{c}0.019 \\
(0.045)\end{array}$ \\
\hline SF-6D from 0.8 to $0.7 *(-0.09)$ & -0.117 & -0.122 & -0.131 \\
\hline
\end{tabular}




\begin{tabular}{|c|c|c|c|}
\hline & $(0.075)$ & $(0.075)$ & $(0.075)^{*}$ \\
\hline \multirow[t]{2}{*}{ SF-6D from 0.8 to $0.7 *(-0.1)$} & -0.082 & -0.102 & -0.102 \\
\hline & $(0.062)$ & $(0.061)+$ & $(0.062)^{*}$ \\
\hline \multirow[t]{2}{*}{ SF-6D from 0.8 to $0.7 *(<-0.1)$} & -0.141 & -0.140 & -0.137 \\
\hline & $(0.024)^{* *}$ & $(0.024)^{* *}$ & $(0.024)^{* *}$ \\
\hline \multirow[t]{2}{*}{ SF-6D from 0.9 to $0.8 *(-0.01)$} & -0.085 & -0.092 & -0.090 \\
\hline & $(0.052)$ & $(0.051)+$ & $(0.052)+$ \\
\hline \multirow[t]{2}{*}{ SF-6D from 0.9 to $0.8 *(-0.02)$} & -0.133 & -0.113 & -0.123 \\
\hline & $(0.105)$ & $(0.103)$ & $(0.104)$ \\
\hline \multirow[t]{2}{*}{ SF-6D from 0.9 to $0.8 *(-0.03)$} & -0.040 & -0.054 & -0.047 \\
\hline & $(0.220)$ & $(0.221)$ & $(0.221)$ \\
\hline \multirow[t]{2}{*}{ SF-6D from 0.9 to $0.8 *(-0.04)$} & 0.055 & 0.053 & 0.050 \\
\hline & $(0.017)^{* *}$ & $(0.017)^{* *}$ & $(0.017)^{* *}$ \\
\hline \multirow[t]{2}{*}{ SF-6D from 0.9 to $0.8 *(-0.05)$} & 0.024 & 0.019 & 0.016 \\
\hline & $(0.063)$ & $(0.064)$ & $(0.064)$ \\
\hline \multirow{2}{*}{ SF-6D from 0.9 to $0.8 *(-0.06)$} & -0.057 & -0.057 & -0.055 \\
\hline & $(0.036)$ & $(0.035)$ & $(0.035)$ \\
\hline \multirow{2}{*}{ SF-6D from 0.9 to $0.8 *(-0.07)$} & 0.056 & 0.047 & 0.043 \\
\hline & $(0.097)$ & $(0.097)$ & $(0.096)$ \\
\hline \multirow[t]{2}{*}{ SF-6D from 0.9 to $0.8 *(-0.08)$} & 0.008 & 0.003 & 0.003 \\
\hline & $(0.028)$ & $(0.027)$ & $(0.027)$ \\
\hline \multirow[t]{2}{*}{ SF-6D from 0.9 to $0.8 *(-0.09)$} & 0.039 & 0.020 & 0.037 \\
\hline & $(0.068)$ & $(0.067)$ & $(0.067)$ \\
\hline \multirow[t]{2}{*}{ SF-6D from 0.9 to $0.8 *(-0.1)$} & -0.006 & -0.010 & -0.011 \\
\hline & $(0.035)$ & $(0.034)$ & $(0.034)$ \\
\hline \multirow{2}{*}{ SF-6D from 0.9 to $0.8 *(<-0.1)$} & 0.022 & 0.013 & 0.013 \\
\hline & $(0.035)$ & $(0.035)$ & $(0.035)$ \\
\hline \multirow[t]{2}{*}{ No change } & 0.035 & 0.035 & 0.030 \\
\hline & $(0.009)^{* *}$ & $(0.009)^{* *}$ & $(0.009)^{* *}$ \\
\hline \multirow[t]{2}{*}{ Major improvement in finances } & 0.123 & 0.125 & 0.126 \\
\hline & $(0.022)^{* *}$ & $(0.022)^{* *}$ & $(0.022)^{* *}$ \\
\hline Control for Employment, Marital & No & Yes & Yes \\
\hline \multicolumn{4}{|l|}{$\begin{array}{l}\text { Status and other socio-economic } \\
\text { factors }\end{array}$} \\
\hline $\begin{array}{l}\text { Control for personal illness, victim } \\
\text { of violence and other life events }\end{array}$ & No & No & Yes \\
\hline N. Observations & 83,556 & 83,530 & 83,177 \\
\hline
\end{tabular}

The independent variables included in the model follow the literature on life satisfaction (see for example Blanchflower and Oswald 2008; Wooden et al. 2009, Green 2011) and the main findings on the covariates included in the model (see Table A12 in the Appendix) are consistent with previous studies (see for example Winkelmann and Winkelmann 1998, Clark et al. 2001; Frey and Stutzer 2000; Frijters et al. 2004; Mendolia and McNamee 2014). Education does not affect life satisfaction, while labour force participation definitively increases life satisfaction, with respect to unemployment. Separated individuals generally show lower levels of life satisfaction, 
and negative life events, such as personal injury, illness or death of a family member or close friend and being a victim of violence, significantly decrease individual life satisfaction.

The compensating income variations associated with changes in SF-6D are presented in Table 4 and 5. The first column shows the CIV ratios, calculated according to (5). For example, a CIV ratio of 1.95 for a SF-6D negative change from 0.7 to 0.6 indicates that the negative life satisfaction effect of this change is equivalent to 1.95 times the positive effect of a major improvement in finances. The second column shows the one-off income windfall that is equivalent to each SF-6D change (for example, over A $\$ 208,000$ for a SF-6D change from 0.7 to $0.6)$.

Table 5 presents CIV associated with changes of different size in SF-6D. As expected, bigger changes are associated with higher monetary values. In particular, the CIV of SF-6D changes increases from $\mathrm{A} \$ 39,486$ for changes equal to 0.04 , to $\mathrm{A} \$ 162,211$ (around USD 124,279) for 0.1 changes in SF-6D.

We have estimated results from the estimation of the impact of health changes on life satisfaction using logarithm of income (rather than unexpected financial improvements), according to equation (2). The coefficients of SF-6D changes are virtually unchanged, but, as expected, the coefficient of logarithm income is substantially downward biased, similarly to what has been showed in Frijters et al. (2011); Brown (2015) and Howley (2017) (Results are not presented for reasons of parsimony but are available from the authors on request).

It is worth noting that the CIV ratios (and corresponding compensating values) would have been substantially overstated if we had not taken into account measurement error in income and endogeneity, as showed in Frijters et al. (2011) and Howley (2017). Alternative CIV estimates (using logarithm of income) are available from the authors on request. 
Table 4 - CIV of Specific Changes in SF-6D (Based on Table 1 - Model 3)

\begin{tabular}{llll}
$\begin{array}{l}\text { Changes in SF-6D from t-1 } \\
\text { to t }\end{array}$ & CIV Ratio & 95\% CI of CIV & CIV Value $(A \$)$ \\
\hline SF-6d from 0.7 to 0.6 & -1.95 & $-2.73 ;-1.17$ & 208,100 \\
SF-6d from 0.8 to 0.7 & -0.96 & $-1.38 ;-0.54$ & 102,449 \\
SF-6d from 0.9 to 0.8 & -0.09 & $-0.27 ; 0.1$ & 9,605 \\
SF-6d from 1 to 0.9 & -0.008 & $-0.51 ; 0.49$ & 854 \\
SF-6D from >0.7 to 0.6 & -1.85 & $-2.57 ;-1.13$ & 197,428 \\
SF-6D from >0.8 to 0.7 & -0.87 & $-1.38 ;-0.36$ & 92,845 \\
SF-6D from >0.9 to 0.8 & -0.01 & $-0.91 ; 0.88$ & 1,067 \\
Other neg. changes (to <0.6) & -4.75 & $-6.46 ;-3.03$ & 506,911 \\
\hline
\end{tabular}

Table 5 - CIV of Changes in SF-6D (Based on Table 2 - Model 3)

All sample

\begin{tabular}{llll}
\hline $\begin{array}{l}\text { Changes in SF-6D from t-1 } \\
\text { to t }\end{array}$ & CIV Ratio & $95 \%$ CI of CIV & CIV Value $(A \$)$ \\
\hline Change equal to - 0.01 & -1.03 & $-1.61 ;-0.44$ & 108,852 \\
Change equal to - 0.02 & -1.03 & $-1.59 ;-0.46$ & 109,920 \\
Change equal to - 0.03 & -1.20 & $-1.94 ;-0.45$ & 128,062 \\
Change equal to - 0.04 & -0.37 & $-0.59 ;-0.14$ & 39,486 \\
Change equal to - 0.05 & -1.48 & $-2.20 ;-0.74$ & 157,943 \\
Change equal to - 0.06 & -1.17 & $-1.66 ;-0.67$ & 124,860 \\
Change equal to - 0.07 & -1.08 & $-1.74 ;-0.42$ & 115,255 \\
Change equal to - 0.08 & -0.81 & $-1.25 ;-0.36$ & 86,442 \\
Change equal to -0.09 & -1.64 & $-2.44 ;-0.84$ & 175,018 \\
Change equal to - 0.1 & -1.52 & $-1.61 ;-0.44$ & 162,211 \\
Change <-0.1 & -1.81 & $-2.45 ;-1.16$ & 193,159 \\
\hline
\end{tabular}




\section{Discussion}

This paper analyses the relationship between changes in health, measured through the SF-6D index and life satisfaction, using the HILDA survey. To the best of our knowledge, this is the first study to estimate the Compensating Income Variation of changes in health. We find that negative changes in SF-6D have a large effect on life satisfaction and that the implied monetary valuations of losses are also substantial.

The negative association between health deterioration and life satisfaction is not unexpected if one considers the various transmission channels through which health status can affect individual well-being. First of all, health itself is a direct input to life satisfaction, through the utility generated from being in good or excellent health. In addition, health deterioration is associated with increased chances of leaving the labour market and this may imply a drop in income, as well as a negative effect on individual perceived role in society. Further, the negative effect of health deterioration may be mediated through a variety of other factors, such as individual perception of her/his own role, self-esteem, lack of personal contacts, etc. Lastly, poor physical and mental health conditions may increase individual stress and therefore the chances of family conflicts, and other problems in personal relationships. These spillover effects may drive further reductions in life satisfaction and health.

The present study adds to the existing literature in several ways (see for example Groot and Maassen van den Brink 2004 and 2006). First, we use a large sample and are able to control for an extensive set of individual characteristics. Second, we address the issue of measurement error in income and therefore are able to generate lower, and possibly more credible, estimates of CIVs. Last, we focus on the monetary value of health losses including negative SF-6D variations of different size. We provide an innovative way to estimate the value of decrements in health, including small changes, which are often more relevant when evaluating health interventions. These smaller changes, and more generally, the valuation of health change, have not received attention in the literature based on QALYs and stated preferences. 
Our estimates are consistent with those calculated in the very few studies that address the problems related to measuring income. For example, Frijters et al. (2011) calculate a CIV for "serious illness" of around A $\$ 105,000$, using data from six waves of HILDA. Further, Fujiwara and Dolan (2014) estimate an annual compensation of GBP£44,237 to compensate individuals affected by depression and anxiety. Lastly, Brown (2015) estimates that moving from good/excellent health to poor/fair health is equivalent to an income loss of $\$ 41,654$ (2010 US dollars).

A potential limitation of our analysis is that the fixed effects estimates only control for timeinvariant effects, and it is possible that other time-varying variables affect both SF-6D and life satisfaction. However, it is difficult to adopt analytical solutions to these problems as there is no quasi-experimental variation that could be used to deal with these issues.

Without further confirmatory studies, we suggest caution be exercised in any exploratory use of these estimates within economic evaluations. Their use would require careful consideration and scrutiny of the comparability of study populations and other design issues, such as similar lengths of follow-up period (Johnston et al 2015). There has been limited use of monetary valuation estimates within an economic evaluation framework, although the number of studies is growing, suggesting that there is interest in use of monetary valuations for policy-making purposes (Fujiwara \& Campbell 2011). Therefore, in terms of future research, it would be useful to validate the estimates produced here with other datasets or other measures, such as the EQ-5D instrument. In addition, there is the potential to explore the longer term effects of income shocks on future changes in health and life satisfaction, to assess whether the effects, and the subsequent valuations, reduce over time. 


\section{References}

Almond, D. 2006. "Is the 1918 influenza pandemic over? Long term effects of in utero influenza exposure in the post 1940s US". Journal of Political Economy 114 (4): 672-712.

Ardelt, M. 1997. "Wisdom and life satisfaction in old age". Journal of Gerontology 52 (1): 15-27.

Asgeirsdottir, T. L., K. H. Birgisdottir, , T. Ólafsdóttir, and Olafsson, S. P. 2017. “A compensating income variation approach to valuing 34 health conditions in Iceland". Economics \& Human Biology 27 (A): 167-183.

$\mathrm{Au}$, N. and D.W. Johnston, 2015. "Too much of a good thing? Exploring the impact of wealth on weight." Health Economics 24 (11): 1403-1421.

Blanchflower, D.G., and A.J. Oswald. 2008. "Is well-being U-shaped over the life cycle?" Social Science \& Medicine 66 (8): 1733-1749.

Brazier J, J.Roberts and M. Deverill 2002. "The estimation of a preference-based measure of health from the SF-36". Journal of Health Economics 21 (2): 271-92.

Brazier J., D. Rowen, I. Mavranezouli, A. Tsuchiya, T.Young, Y. Yang, M. Barkham, and R. Ibbotson. 2012. "Developing and testing methods for deriving preference-based measures of health from condition-specific measures (and other patient-based measures of outcome)." Health Technology Assessment 16 (32): 1-113.

Brown, T. 2015. "The Subjective Well-Being Method of Valuation: An Application to General Health Status". Health Services Research 50 (6): 1996-2018.

Carroll, N., P. Frijters, and M. Shields. 2009. "Quantifying the costs of drought: new evidence from life satisfaction data.” Journal of Population Economics 22 (2): 445-461.

Cawley, J, and C. Meyerhoefer. 2012. "The medical care costs of obesity: an instrumental variables approach." Journal of Health Economics 31 (1): 219-30.

Chuck, A., P. Jacobs, A. Ohinmaa, B. Dick, and S. Rashiq. 2009. "The willingness to pay for reducing pain and pain-related disability." Value in Health 12 (4): 498-506.

Clark, A., Y. Georgellis, and P. Sanfey. 2001. "Scarring: the psychological impact of past unemployment." Economica 68 (270): 221-241.

Clark, A., P. Frijters, and M. Shields. 2008 "Relative Income, Happiness and Utility: An Explanation for the Easterlin Paradox and Other Puzzles.” Journal of Economic Literature 46 (1): 95-144.

Claxton, K., S. Martin, M. Soares, N. Rice, E. Spackman, S. Hinde, N. Devlin, P. Smith, and M. Sculpher. 2015. "Methods for the estimation of the National Institute for Health and Care Excellence cost-effectiveness threshold." Health Technology Assessment 19 (14): 1-503.

Eisenberg, D., E. Golberstein, J. Whitlock, and M. Downs, M. 2013. "Social contagion of mental health: evidence from college roommates." Health Economics 22 (8): 965-986.

Ferrer-I-Carbonell, A. and B. van Praag, 2002. "The subjective costs of health losses due to chronic diseases. An alternative model for monetary appraisal.” Health Economics 11 (8): 709-722.

Fletcher, J.M. 2010. "Social interactions and smoking: evidence using multiple student cohorts, instrumental variables and school fixed effects." Health Economics 19 (4): pp. 466-484.

Frey, B., and A. Stutzer. 2000. "Happiness, economy and institutions”. Economic Journal, 110 (466), 918-938. 
Frijters, P., J. Haisken DeNew, and M. Shields. 2004. "Investigating the patterns and determinants of life satisfaction in Germany following reunification." The Journal of Human Resources 39 (3): 649674.

Frijters, P., D. Johnston, and M. Shields. 2011. "Life Satisfaction Dynamics with Quarterly Life Event Data." Scandinavian Journal of Economics 113 (1): 190-211.

Fujiwara, D., and P. Dolan. 2014. "Valuing mental health: how a subjective wellbeing approach can show just how much it matters." UK Council for Psychotherapy.

Fujiwara, D., and R. Campbell. 2011. "Valuation techniques for social cost-benefit analysis: stated preference, revealed preference and subjective well-being approaches". HM Treasury \& Department for Work \& Pensions. London: HMSO.

Green, F. 2011. "Unpacking the misery multiplier: How employability modifies the impacts of unemployment and job insecurity on life satisfaction and mental health." Journal of Health Economics 30 (2): 265-276.

Grosse, S. 2008. "Assessing cost-effectiveness in healthcare: history of the $\$ 50,000$ per QALY threshold”. Expert Review of Pharmacoeconomics Outcomes Research 8 (2): 165-178.

Groot, W., and HM. Massen van den Brink. 2004. "A direct method for estimating the compensating income variation for severe headache and migraine”. Social Science and Medicine 58 (2): 305-314.

Groot, W., and HM. Massen van den Brink. 2006. "The compensating income variation of cardiovascular disease." Health Economics 15 (10): 1143-1148.

Groot, W., HM. Massen van den Brink, and B. Van Praag. 2007. "The compensating income variation of social capital.” Social Indicator Research 82 (2): 189-2007.

Hasmi, J., and K. Davis. 2009. "Women experience greater heat pain adaptation and habituation than men.” Pain 145 (3): 350-357.

Heckman, J.J. 1979. "Sample selection bias as a specification error". Econometrica 47 (1): 153-161.

Howley, P. 2017. "Less money or better health? Evaluating individual's willingness to make tradeoffs using life satisfaction data". Journal of Economic Behavior \& Organization 135 (1): 53-65.

Johnson, F.R., M.R. Banzhaf, and W.H. Desvousges. 2000. "Willingness to pay for improved respiratory and cardiovascular health: a multiple-format, stated-preference approach." Health Economics 9 (4): 295-317.

Johnston, R.J., J. Rolfe, R.S. Rosenberger, and R. Brouwer. 2015. "Introduction to benefit transfer methods." In: Benefit Transfer and Resource Values: A Guide for Researchers and Practitioners, edited by Johnston, R.J., Rolfe, J., Rosenberger, R.S., Brouwer, R. (Eds.). Dordrecht, Springer.

Johnstorn, D., M. Shields, and A. Suziedelyte. 2017. "Victimisation, Wellbeing and Compensation: Using Panel Data to Estimate the Costs of Violent Crime." The Economic Journal. 128 (611): 15451569.

Kløjgaard, M., C. Manniche, L. Bjørnskov-Pedersen, M. Bech, and R. Søgaard. 2014. "Patient Preferences for Treatment of Low Back Pain-A Discrete Choice Experiment." Value in Health 17 (4): 390-396.

Loomis, J. 2014. “2013 WAEA Keynote Address: Strategies for Overcoming Hypothetical Bias in Stated Preference Surveys.” Journal of Agricultural and Resource Economics 39 91): 34-46.

McVicar, D., and A. Polanski. 2014. "Peer Effects in UK Adolescent Substance Use: Never Mind the Classmates?" Oxford Bulletin of Economics and Statistics 76 (4): 589-603. 
Mentzakis E, P. McNamee, M. Ryan, and M. Sutton. 2012. "Valuing informal care experience: does choice of measure matter?” Social Indicators Research 108 (1): 169-184.

McNamee P., and S. Mendolia. 2014. "The effect of chronic pain on life satisfaction: Evidence from Australian data." Social Science and Medicine 121 (3): 65-73.

Murray, M. 2006. "Avoiding invalid instruments and coping with weak instruments." Journal of Economic Perspectives 20 (4): 111-132.

National Institute for Health and Care Excellence (NICE). 2013. "Guide to the methods of technology appraisal.” http://www.nice.org.uk/article/pmg9/chapter/Foreword.

Nimdet, K., N. Chaiyakunapruk., K. Vichansavakul, and S. Ngorsuraches. 2015. "A Systematic Review of Studies Eliciting Willingness-to-Pay per Quality-Adjusted Life Year: Does It Justify CE Threshold?" PLoS ONE 10(4): e0122760. doi:10.1371/journal.pone.0122760.

Norman, R., R. Viney, J. Brazier, L. Burgess, P.Cronin, M. King, J. Ratcliffe, and D. Street. 2014. "Valuing SF-6D Health States Using a Discrete Choice Experiment." Medical Decision Making 34 (6): 773-786.

Oswald, A., and N. Powdthavee. 2008. "Does happiness adapt? A longitudinal study of disability with implications for economists and judges." Journal of Public Economics 92 (5-6): 1061-1077.

Pelo, S. Gasparini G, Garagiola U., Cordaro M., Di Nardo F., Staderini E., Patini R., de Angelis P., D'Amato G., Saponaro G., Moro A. 2017. "Surgery-first orthognathic approach vs traditional orthognathic approach: Oral health-related quality of life assessed with 2 questionnaires." American Journal of Orthodontics and Dentofacial Orthopedics 152 (2): 250-254.

Powdthavee, N., 2009. "How much does money really matter? Estimating the causal effect of income on happiness." Empirical Economics 39 (1): 77-92.

Powdthavee, N., and B. van den Berg. 2011. "Putting different price tags on the same health condition: Re-evaluating the well-being valuation approach." Journal of Health Economics 30 (5): 1032-1043.

Rees, D., and J. Saabia, 2011. "The effect of migraine headache on educational attainment." Journal of Human Resources 46 (2): 317-332.

Trogdon, J., J. Nonnemaker, and J. Pais. 2008. "Peer Effects in Adolescent Overweight." Journal of Health Economics 27 (5): 1388-99.

Walters, S.J., and J. Brazier. 2003. "What is the relationship between the minimally important difference and health state utility values? The case of the SF-6D." Health and Quality of Life Outcomes 1 (4): 1-8.

Walters, S.J., and J. Brazier. 2005. "Comparison of the minimally important difference for two health state utility measures: EQ-5D and SF-6D.” Quality of Life Research 14 (6) : 1523-1532.

Whitehead, S., and S. Ali. 2010. "Health outcomes in economic evaluation: the QALY and utilities." British Medical Bulletin 96 (1): 5-21.

Winkelmann, L, and R. Winkelmann. 1998. "Why are the unemployed so unhappy? Evidence from panel data." Economica 65 (257): 1-17.

Wooden, M., and N. Watson. 2002. "The Household, Income and Labour Dynamics in Australia (HILDA) survey: An introduction.” Australian Social Policy 2001-02: 79-100.

Wooden, M., D. Warren, and R. Drago. 2009. "Working time mismatch and subjective well-being." British Journal of Industrial Relations 47 (1): 147-179. 